\title{
Defining the biomethane potential (BMP) of solid organic wastes and energy crops: a proposed protocol for batch assays
}

\author{
I. Angelidaki, M. Alves, D. Bolzonella, L. Borzacconi, J. L. Campos,
}

A. J. Guwy, S. Kalyuzhnyi, P. Jenicek and J. B. van Lier

\section{ABSTRACT}

The application of anaerobic digestion technology is growing worldwide because of its economic and environmental benefits. As a consequence, a number of studies and research activities dealing with the determination of the biogas potential of solid organic substrates have been carrying out in the recent years. Therefore, it is of particular importance to define a protocol for the determination of the ultimate methane potential for a given solid substrates. In fact, this parameter determines, to a certain extent, both design and economic details of a biogas plant. Furthermore, the definition of common units to be used in anaerobic assays is increasingly requested from the scientific and engineering community. This paper presents some guidelines for biomethane potential assays prepared by the Task Group for the Anaerobic Biodegradation, Activity and Inhibition Assays of the Anaerobic Digestion Specialist Group of the International Water Association. This is the first step for the definition of a standard protocol.

Key words | anaerobic digestion, batch assays, biomethane potential (BMP), energy crops, organic solid waste

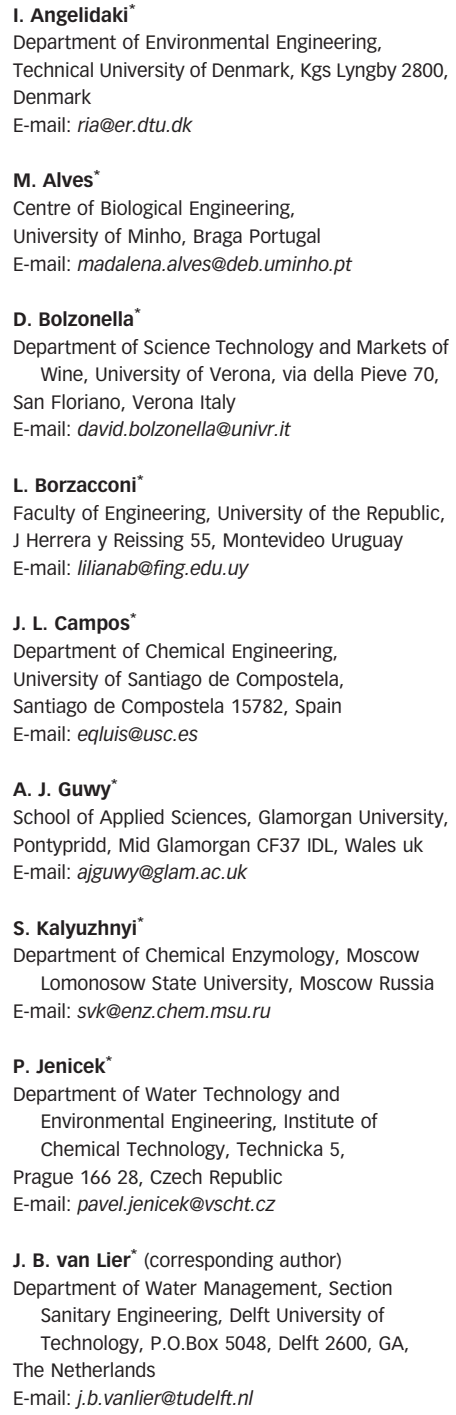

J. B. van Lier ${ }^{*}$ (corresponding author) Department of Water Management, Section Sanitary Engineering, Delft University of Technology, P.O.Box 5048, Delft 2600, GA The Netherlands

E-mail: j.b.vanlier@tudelft.nl

*TG-ABAI-Task Group for the Anaerobic Biodegradation, Activity and Inhibition of the Anaerobic Digestion Specialist Group of the International Water Association. doi: 10.2166/wst.2009.040 


\section{INTRODUCTION}

Anaerobic digestion of solid organic waste such as biowaste, sludge, cattle manure, energy crops and other biomasses, for bio-energy production is a widely applied technology. Because of the increasing request for renewable energy production it is gaining more and more appeal and consideration also among decision makers. A consequence of the increasing implementation of this technology is the necessity to determine the ultimate biogas potential for several solid substrates. In fact, this is a key parameter for assessing design, economic and managing issues for the full scale implementation of anaerobic digestion processes.

In last 30 years a huge amount of papers dealing with anaerobic biodegradability tests for substrates of different origin has been published. According to ISI web database, the number of published papers dealing with biomethane potential (BMP) tests in referenced journals passed from 7 in 1991 to 70 in 2007, demonstrating the increasing interest in this field of research. Despite a mass of data having been generated, comparison of biodegradability data in the literature is very difficult. This is not only due to the variety of equipment used, but also to the many different environmental conditions and protocols that are used. For example, the inoculum-nutrients mix, liquid and headspace volumes, $\mathrm{pH}$, headspace pressure and the detection system can all differ from on test to another. Moreover, the results are often presented in variable units making comparison very difficult.

Some papers were dedicated to these aspects: Owens \& Chynoweth (1993), Angelidaki \& Sanders (2004) and Hansen et al. (2004), proposed comprehensive protocols for the determination of the biomethane potential of organic wastes, while other authors focused on specific problems like the substrate-inoculum ratio (Fernandez et al. 200I; Neves et al. 2004; Raposo et al. 2006) or very specific substrates (Lin et al. I999; Raposo et al. 2006).

However, the definition of a standard protocol is a challenge as the process of anaerobic degradation is a highly complex and dynamic system where microbiological, biochemical and physico-chemical aspects are closely linked. The process involves the hydrolysis of complex high molecular weight carbohydrates, fats and/or proteins into soluble polymers by means of the enzymatic action of hydrolytic fermentative bacteria and the conversion of these polymers into organic acids, alcohols, $\mathrm{H}_{2}$ and $\mathrm{CO}_{2}$. Volatile fatty acids (VFAs) and alcohols are then converted to acetic acid by the $\mathrm{H}_{2}$-producing acetogenic bacteria and finally methanogenic bacteria convert acetic acid and $\mathrm{H}_{2}$ gas into $\mathrm{CO}_{2}$ and $\mathrm{CH}_{4}$. The stability of the process is dependent on the critical balance that exists between the symbiotic growth of the principal metabolic groups of bacteria i.e. acid forming bacteria, obligate hydrogen producing acetogens and methanogens.

According to this scenario, the definition of a common protocol for the definition of BMP is strongly requested by both the professional and research world.

As a result of that need, a task group (TG) on Anaerobic Biodegradation, Activity and Inhibition (ABAI) was proposed to be created during the $2001 \mathrm{AD}$ conference at Antwerp, Belgium. The main initiative and force was proposed by Prof. Alberto Rozzi of the Polytechnic of Milan, Italy (Rozzi \& Remigi 2004).

A number of different assays described as ISO standards, have been formulated for the last 20 years (Muller et al. 2004). At first, these methods can be shared in two main groups: one group deals with the definition of anaerobic biodegradability of chemical compounds or plastic (ISO 14853 -1999; ASTM D 5511-1994; ASTM 5210 -1992; ASTM E 2170- 2001; ISO 15473-2002 and others) while another group deals with the ultimate biodegradability of complex organic substrates and biogas production (ISO 11734-1995; ISO/DIS 14853-1999; UK Environment Agency 2005 and others). Basically, they differ for the experimental set up. This generated different results, generally not comparable. Additionally, all these methods previously reported in official documents still contain some important inconsistencies or mistakes. However, these methods are used differently and often modified by researchers to define the anaerobic biodegradability of organic compounds. Therefore, it is opinion of the ABAI-TG that a standard protocol is needed to unify and standardise assays in order to gain comparable results.

In this paper some issues important for the definition of the ultimate BMP of solid substrate determined in batch 
assays are discussed and some basic guidelines for a common protocol are given. The objective of the present paper, which is the result of several years of activity in the field of anaerobic digestion of the Group participants, is to provide important experimental guidelines for the reliable and reproducible assessment of the anaerobic biodegradability of any compound or undefined material to methane and carbon dioxide, with particular emphasis for solid organic substrates such as biowaste, energy crops, agrowaste, manure, sludge and other substrates.

\section{METHODS FOR THE PROPOSED PROTOCOL}

The important remarks of the proposed guidelines are reported here below in an itemised form.

\section{Substrate}

Substrate should be characterised as thoroughly as possible. In particular, the total solids (TS) and volatile solids (VS), chemical oxygen demand (COD), nitrogen and phosphorus should be always determined. Then, the COD/VS ratio, which is typically consistent with the characteristics of a given substrate, can be calculated. Clearly, the determination of COD for solid heterogeneous substrates is always difficult and open to some uncertainty (Buffiere et al. 2006; Raposo et al. 2008).

Another important characteristic is the content of lignin, cellulose and hemi-cellulose which, in particular for energy crops and agro-waste, should always be considered in the characterisation mainly due to the un-degradability of lignin which is not contributing to biogas potential of the substrate (Buffiere et al. 2006).

All the data dealing with the substrate characterisation should be reported in the final assay report.

In the case of an acidic waste, for example, putrescible kitchen waste, attention should be given during drying of the sample as volatile compounds can be lost during TS determination. In this case VS can be underestimated due to VFA losses during the analysis of total solids. For materials such as this, the TS determination should be made after increasing the $\mathrm{pH}$ of the waste to decrease volatility of volatile fatty acids. Additionally, for very volatile samples, drying during TS determination should be performed at a maximum temperature of $90^{\circ} \mathrm{C}$ instead of $105^{\circ} \mathrm{C}$, until constant weight. Also the COD or TOC value of the sample substrate should be determined.

\section{Particle size of the substrate}

Size can be a very important parameter in the rate of biogas production rather than for the ultimate biogas production from a given substrate. Therefore, the size of the substrate particles is considered to be fundamental for kinetic studies (Sanders 200I; Vavilin \& Angelidaki 2005) rather than for the BMP determination. However, some literature (Palmowski \& Muller 2000; Perez-Lopez et al. 2005) showed how the BMP determination can be influenced by this parameter and a standardization of the particles size can be recommended to increase the reproducibility of the BMP test for some heterogeneous substrates (PabonPereira et al. 2009).

\section{Inoculum}

The inoculum should be "fresh" from any type of active anaerobic reactor, e.g. sludge reactors, manure-based biogas reactors or sludge bed reactors, such as UASB and a "broad trophic" microbial composition in order to secure that different substrates would not face any limitations. This should be homogenous and large materials other than biomass (e.g., stones, wood) removed. In case the reactor where the inoculum is originating from has very simple feed composition, different inocula should be mixed, e.g. digested sewage sludge together with granules. Either mesophilic or thermophilic inocula can be used, depending on the temperature of the assay to be carried out.

The inoculum should be "degassed", i.e. pre-incubated in order to deplete the residual biodegradable organic material present in it. The pre-incubation should be done at the same temperature as the process temperature, where the inoculum was originating from. Degassing should be protracted until no significant methane production: typically 2 to 5 days of incubation. In some cases, e.g. when the inoculum is taken from a reactor fed with relatively high fat/oil concentration, higher periods of pre-incubation may be required, in order to eliminate all the residual 
(adsorbed/entrapped) substrate. The inoculum should be as closely representative as that taken from the reactor, and should not be washed to remove residual substrate material and inorganic carbon compounds as described on previous ISO 11734, ASTM E 2170 (2001).

\section{Inoculum activity}

The quality of the inoculum should be checked by performing activity tests on acetate and cellulose. The inoculum should have a minimum specific activity on acetate of $0.1 \mathrm{~g} \mathrm{CH}_{4}$-COD/g VSS.d for sludge and $0.3 \mathrm{~g}$ $\mathrm{CH}_{4}$-COD/g VSS.d for granular sludge. According to the experiences of the authors, for determination of activities of different trophic groups, model substrates are usually chosen (Table 1).

As substrates for methanogenic activity, $\mathrm{H}_{2} / \mathrm{CO}_{2}$ (1 atm overpressure) or $1 \mathrm{~g} / \mathrm{l}$ acetic acid are suggested for hydrogenotrophic and acetoclastic methanogenic activity, respectively. For estimation of acetogenic activities, $0.5 \mathrm{~g} / 1$ propionic and butyric acid are suggested. For determination of acidogenic activity, $1 \mathrm{~g} / \mathrm{l}$ glucose can be used as substrate, while, for hydrolytic activities, $1 \mathrm{~g} / 1$ cellulose for cellulolytic activity and $1 \mathrm{~g} / 1$ casein for proteolytic activity are recommended.

The kinetic behaviour is represented by a zero order model when the inoculum concentration $\left(\mathrm{X}_{\mathrm{O}}\right)$ is higher than the amount of biomass produced during the activity test $\left(\mathrm{Y}_{\mathrm{SX}} \cdot\left(\mathrm{S}_{\mathrm{O}}-\mathrm{S}\right)\right)$. Therefore, the inoculum concentration should always be high compared to that of the substrate (in term of volatile solids) and the substrate to inoculum (S/I) ratio

Table 1 | Suggested model substrates for determination of activities of different trophic groups in a biogas reactor

\begin{tabular}{ll} 
Population & Initial substrate concentration proposed \\
\hline Hydrolytic & $1 \mathrm{~g}$ amorphous cellulose/L \\
Acidogenic & $1 \mathrm{~g}$ glucose/L \\
Proteolytic & $1 \mathrm{~g}$ casein/L \\
Acetogenic & $0.5 \mathrm{~g}$ propionic/L; $0.5 \mathrm{~g}$ n-butyric/L \\
Acetoclastic & $1 \mathrm{~g} \mathrm{acetic} \mathrm{acid} / \mathrm{L}$ \\
Hydrogenotrophic & overpressure of $1 \mathrm{~atm}$ of a mixture of \\
& $\mathrm{H}_{2} / \mathrm{CO}_{2}(80 / 20)$ \\
\hline
\end{tabular}

should be recognised as one of the major parameter affecting the results of anaerobic assays (Neves et al. 2004).

The relative volume of inoculum to be used in the assays can vary a lot, depending on the activity and biomass concentration of the inoculum and on substrate concentration and biodegradability. The relative volume of inoculum, can be lower in case that concentrated/dense inocula are used such as granules containing a concentrated amount of active microorganisms, while much higher relative volumes of inocula are need in case of less dense inocula such as digested manure or sewage sludge. In any case the amount of inoculum should be enough to prevent the accumulation of volatile fatty acids and acidic conditions.

The volume of inoculum can also be estimated by a simple mass balance provided the hydrolysis rate and biomass activity are known or estimated. For example, according to Angelidaki \& Sanders (2004) the volume of inoculum can be determined as:

$V_{\text {inoculum }}=\frac{X_{S S} V_{\text {ww }} k_{h}}{V S S_{\text {inoculum }} S M A_{\text {inoculum }}}$

where,

$\mathrm{X}_{\mathrm{SS}}$ is the concentration of hydrolysable substrate in the waste(water) $(\mathrm{g} / \mathrm{L}), \mathrm{V}_{\mathrm{ww}}$ is the volume of waste(water) in the assay vessel $(\mathrm{L}), \mathrm{k}_{\mathrm{h}}$ is the first order hydrolysis constant $\left(\right.$ day $\left.^{-1}\right)$, VSS $_{\text {inoculum }}$ is the VSS content of the inoculum (gVSS/L) and $\mathrm{SMA}_{\text {inoculum }}$ is the specific methanogenic activity of the inoculum (g COD- $\mathrm{CH}_{4} / \mathrm{g}$ VSS.day).

This equation can be eventually modified to take into account the presence of soluble COD for substrates rich in organic compounds in the liquid phase.

\section{Medium}

Necessary nutrients/micronutrient/vitamins are needed for optimal function of anaerobic microorganisms. This is of particular importance for some kind of solid substrates and energy crops which can be deficient in some micronutrients (Lindorfer et al. 2007). Nutrient medium containing macromicronutrients buffers vitamins etc. should be added, unless it can be documented that are present in inoculum or substrate. Table 2 reports a typical basic medium for batch tests. 
Table 2 | Basic Anaerobic Medium (Angelidaki \& Sanders 2004)

Description of Anaerobic Basic Medium

The basic medium is prepared from the following stock solutions (chemicals given below are concentrations in $\mathrm{g} / \mathrm{l}$ in distilled water).

$\mathrm{NH}_{4} \mathrm{Cl}, 100 ; \mathrm{NaCl}, 10 ; \mathrm{MgCl}_{2} 6 \mathrm{H}_{2} \mathrm{O}, 10 ; \mathrm{CaCl}_{2} 2 \mathrm{H}_{2} \mathrm{O}, 5$

$\mathrm{K}_{2} \mathrm{HPO}_{4} 3 \mathrm{H}_{2} \mathrm{O}, 200$

resazurin 0.5

trace-metal and selenite solution: $\mathrm{FeCl}_{2} 4 \mathrm{H}_{2} \mathrm{O}, 2 ; \mathrm{H}_{3} \mathrm{BO}_{3}, 0.05 ; \mathrm{ZnCl}_{2}, 0.05 ; \mathrm{CuCl}_{2} 2 \mathrm{H}_{2} \mathrm{O}, 0.038 ; \mathrm{MnCl}_{2} 4 \mathrm{H}_{2} \mathrm{O}, 0.05 ;\left(\mathrm{NH}_{4}\right)_{6} \mathrm{Mo}_{7} \mathrm{O}_{24}$ $4 \mathrm{H}_{2} \mathrm{O}, 0.05 ; \mathrm{AlCl}_{3}, 0.05 ; \mathrm{CoCl}_{2} 6 \mathrm{H}_{2} \mathrm{O}, 0.05 ; \mathrm{NiCl}_{2} 6 \mathrm{H}_{2} \mathrm{O}, 0.092$; ethylenediaminetetraacetate, 0.5; concentrated $\mathrm{HCl}, 1 \mathrm{ml} ; \mathrm{Na}_{2} \mathrm{SeO}_{3}$ $5 \mathrm{H}_{2} \mathrm{O}, 0.1$

vitamin mixture (componets are given in $\mathrm{mg} / \mathrm{l}$ ): Biotin, 2; folic acid, 2; pyridoxine acid, 10; ridoflavin, 5; thiamine hydrochloride, 5; cyanocobalamine, 0.1; nicotinic acid, 5; P-aminobenzoic acid, 5; lipoic acid, 5; DL-pantothenic acid.

To $975 \mathrm{ml}$ of distilled water, the following stock solutions should be added (A), $10 \mathrm{ml}$; (B), $2 \mathrm{ml}$; (C), $1 \mathrm{ml}$; (D), $1 \mathrm{ml}$ and (E), $1 \mathrm{ml}$. The mixture is gassed with $80 \% \mathrm{~N}_{2}-20 \% \mathrm{CO}_{2}$ mixture to maintain a neutral $\mathrm{pH}$. Cysteine hydrochloride, $0.5 \mathrm{~g}$ and $\mathrm{NaHCO}_{3}, 2.6 \mathrm{~g}$ dissolved in $10 \mathrm{ml}$ distilled water are added and the medium is dispensed to serum vials and autoclaved if necessary. Before inoculation the vials are reduced with $\mathrm{Na}_{2} \mathrm{~S} 9 \mathrm{H}_{2} \mathrm{O}$ to a final concentration of $0.025 \%$.

It is important that stock solutions are added to water, and not the contrary, to prevent precipitations phenomena.

\section{Blank and controls}

The background methane production from the inoculum, determined in blank assays with medium or water and no substrate, is subtracted from the methane production obtained in the substrate assays. The blank assay can be carried out in triplicate for statistical significance. The control procedure is due to one or more vessels with cellulose standard substrate or gelatine or both depending on the nature of the tested substrate: cellulose can be used for crops, agro-waste or municipal biowaste, while gelatine is preferable for meat, fish and other similar wastes. The control assays give an idea of the inoculum response toward "standard" substrates.

\section{Replicates}

The number of replicates should be at least three for each dilution or more, depending on the complexity of the substrate and reproducibility of the tests. This allows for statistical analysis of the collected data and guarantees the reproducibility of the assays.

\section{Mixing}

Mixing facilitates the contact between bacteria/enzymes and substrates preventing the accumulation of substrates and intermediate (e.g., fatty acids) in the medium and guarantee homogeneous conditions in the assays vessels. Mixing can be very different for BMP assays: turn up down once a day for large flasks or continuous for small tubes. It can be an important parameter when collecting data for both BMP determination and kinetic studies (Vavilin et al. 2008).

\section{Assay experimental set up}

The assay should be performed at least in triplicate at each dilution used, depending on the complexity (homogeneity) of the substrate and reproducibility of the tests. When using substrates with high heterogeneity more than three replicates should be used to gain reliable results.

The assay is performed in closed vessels $(100 \mathrm{ml}$ up to 2 litres) depending on the homogeneity of the substrate (Figure 1).

For new substrates with unknown degradation characteristics, a number of different dilutions of the substrate (with water) are required. Dilutions ensure that the methane potential of the substrates is not underestimated due to overload or potential inhibition. Samples should be tested at concentrations from $5 \%$ to $100 \%$ (undiluted samples). When the maximum methane potential is the same in at least two different dilutions of the dilution series, it can be assumed that the inoculum is not overloaded or inhibited. If the specific potential continues to increase with 

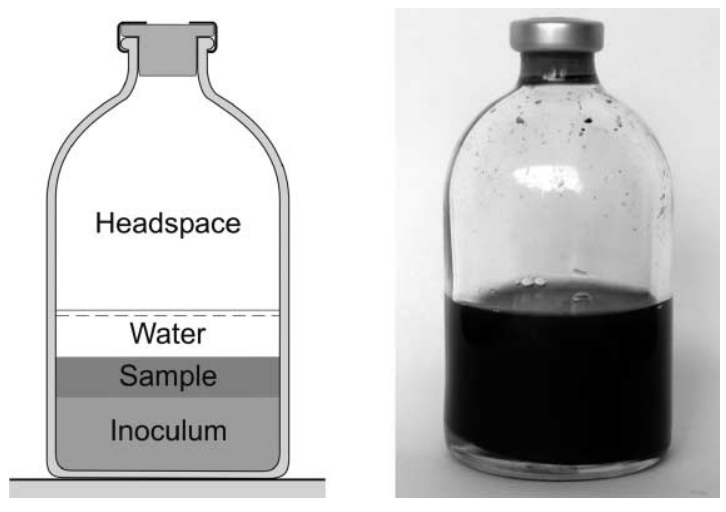

Figure 1 | Suggested assay vessel for anaerobic biodegradability test

increasing dilution (decreased concentration of substrate), additional dilutions are required.

The assay vessels should be flushed continuously with $\mathrm{N}_{2} / \mathrm{CO}_{2} \quad(80 / 20 \%$ as volume) before transferring the substrate and inoculum accurately either by volume or weight, depending on its consistency It should be continuously stirred and kept under anaerobic conditions during the process of transfer. Typically $\mathrm{N}_{2} / \mathrm{CO}_{2} \quad(80 / 20 \%$ as volume) is flushed in the headspace of the inoculum storage vessel. Also assay vessels are flushed using the same gas. The use of the medium described in Table 2 and of this gas mixture allows for keeping the $\mathrm{pH}$ at neutrality at the beginning of the assays. The medium can be transferred directly or diluted with water (see medium description). The transfer of inoculum is typically achieved by using a graduated $100 \mathrm{ml}$ syringe with a large orifice with attached tubing to reach the bottom of the inoculum storage bottle. In the case of granular inoculum, the granules are first drained using a suitable sieve which has a sufficient mesh size to retain the granules. Once drained of liquid, a specific granular volume can be transferred using a spoon, ensuring that the same volume is distributed to each assay vessel. After transferring the inoculum, substrate and medium the assay vessels are closed with a thick butyl rubber stopper which is hold in place by sealing with an aluminium crimp.

\section{Data collection}

The result of a BMP test is the definition of the methane (or biogas) produced from a given weight of a certain substrate. Gas can be measured by means of different techniques: volumetric methods (typically acidic water displacement), manometric (determination of pressure variation by transducers), gas-chromatographic methods with flame ionization (FID) or thermal conductivity (TCD) detectors. In these guidelines the methane accumulated in the headspace of the closed vessel is measured by gas chromatography (GC). For that, a sample volume of e.g. $100 \mu \mathrm{L}$ should be collected with a gas-tight syringe and injected into the GC. The obtained peak area should be compared to that obtained by injecting the same volume of a standard gas mixture of known composition. The standard gas mixture should be injected at the atmospheric pressure because if the gas sample is taken with a gas tight over pressurised syringe, and compared with a gas standard injected under atmospheric pressure the methane (\%) will be more than $100 \%$.

The volume of methane produced is obtained by multiplying the headspace volume by the (\%) of $\mathrm{CH}_{4}$ in the headspace as determined by GC analysis.

For publication and comparison with other studies, the values should be calculated to standard temperature and pressure (STP) conditions, i.e., converted to $0^{\circ} \mathrm{C}$ and $1 \mathrm{~atm}$.

\section{Data interpretation and reporting}

The BMP results should always be accompanied by a clear description of inoculum source, activity and VS or VSS content, medium composition, waste(water) composition or description, and dilutions used. The methane production profiles with respect to time together with the profiles for the blank and control assays should be presented.

In the final report, the following items should be considered:

- date, time of start and end of the test;

- tested substrate, amount or quantity and physicalchemical characteristics;

- inoculum, origin and activity, amount or quantity and chemical-physical characteristics;

- test conditions: temperature, substrate/inoculums (S/I) ratio, volume of the vessel, number of replicates;

- results of blank and controls methane production (report graphics);

- methane production in the triplicate and relative average and standard deviations for a complete statistical analysis of data obtained; 
- specific methane production: this can be reported as volume of $\mathrm{CH}_{4}$ per gram VS, or $\mathrm{CH}_{4}$ per gram $\mathrm{COD}$, or $\mathrm{CH}_{4}$ per gram of sample.

Figure 2 gives a typical example of how the graphs appear in such assays.

Results from BMP tests, if properly obtained and of good quality, can be used to obtain further information on the substrate studied like the hydrolysis rate provided that hydrolysis is limiting the anaerobic conversion process. In fact, using the first part of the experimental curve build for the determination of the ultimate methane production of a given substrate (e.g., the first five days of the example given in Figure 2), it is possible to define the constant $k_{\mathrm{h}}\left(\mathrm{day}^{-1}\right)$ for a first order hydrolysis model:

$\frac{\mathrm{d} S}{\mathrm{~d} t}=-k_{h} S$

where, $\mathrm{S}$ is the biodegradable substrate, $t$ the time and $k_{\mathrm{h}}$ the first order hydrolysis constant.

Once the variable are separated and integrated and the existing relation between the biodegradable substrate and the methane generated is taken into account, it is then possible to write:

$\ln \frac{B_{\infty}-B}{B_{\infty}}=-k_{h} t$

Where $\mathrm{B}_{\infty}$ is the value of the ultimate methane production and where $\mathrm{B}$ is the methane produced at a given time, $t$.

Now, the value of the first order hydrolysis constant, $k_{\mathrm{h}}$, can be determined as the slope of the linear curve obtained.

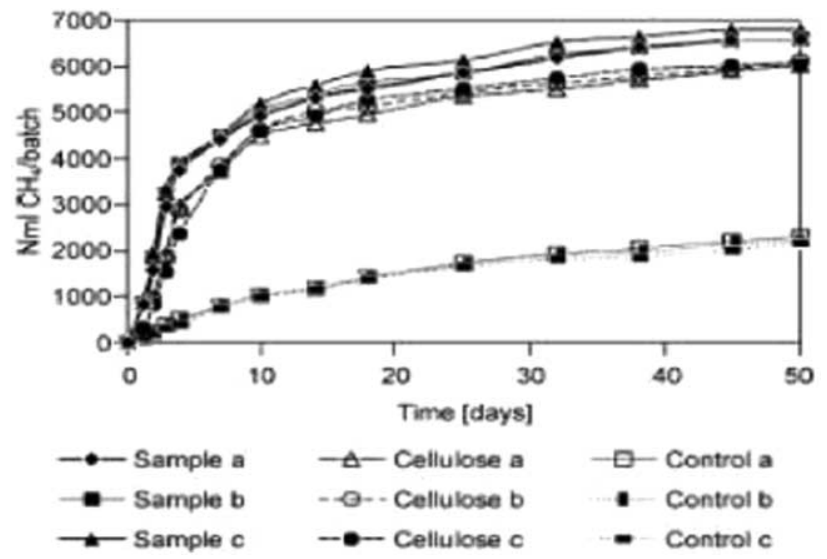

Figure 2 | Methane production curves for triplicate samples of solid organic substrate (household), cellulose and inoculum (control). From Hansen et al. 2004.
This value is characteristic of a given substrate and gives information about the time required to generate a given ratio of the ultimate methane potential (Mace et al. 2003).

\section{CONCLUSIONS}

The necessity of defining the methane potential of a given solid organic substrate originated several standard and nonstandard methods for the definition of ultimate methane formation.

In order to give some basic guidelines for researchers involved in batch tests for the determination of the BMP value, the TG-ABAI-Task Group for the Anaerobic Biodegradation, Activity and Inhibition of the Anaerobic Digestion Specialist Group of the International Water Association, produced a report on anaerobic assays for the determination of biodegradability, activity, inhibition and matrices bio-stability.

This paper presented some guidelines and advices to researchers involved in such experiments to try to unify the use of units and techniques in future studies.

\section{REFERENCES}

Angelidaki, I. \& Sanders, W. 2004 Assessment of the anaerobic biodegradability of macropollutants. Rev. Environ. Sci. Biotechnol. 3(2), 117.

Buffiere, P., Loisel, D., Bernet, N. \& Delgenes, J. P. 2006 Towards new indicators for the prediction of solid waste anaerobic digestion properties. Water Sci. Technol. 53(8), 233-241.

Fernandez, B., Porrier, P. \& Chamy, R. 20or Effect of inoculumsubstrate ratio on the start-up of solid waste anaerobic digesters. Water Sci. Technol. 44(4), 103-108.

Guwy, A. J. 2004 Equipment used for testing anaerobic biodegradability and activity. Rev. Environ. Sci. Biotechnol. 3(2), 131-139.

Hansen, T. L., Schmidt, J. E., Angelidaki, I., Marca, E., Jansen, J. C., Mosbæk, H. \& Christensen, T. H. 2004 Measurement of methane potentials of solid organic waste. Waste Manage. 24(4), 393-400.

Lin, J. G., Ma, Y. S., Chao, A. C. \& Huang, C. L. 1999 BMP test on chemically pretreated sludge. Bioresour. Technol. 68(2), $187-192$.

Lindorfer, H., Pérez López, C., Resch, C., Braun, R. \& Kirchmayr, R. 2007 The impact of increasing energy crop addition on process performance and residual methane potential in anaerobic digestion. Water Sci. Technol. 56(10), 55-63. 
Mace, S., Bolzonella, D., Cecchi, F. \& Mata-Alvarez, J. 2003 Comparison of the biodegradability of the grey fraction of municipal solid waste of Barcelona in mesophilic and thermophilic conditions. Water Sci. Technol. 48(4), 21-28.

Muller, W., Frommert, I. \& Jōrg, R. 2004 Standardized methods for anaerobic biodegradability testing. Rev. Environ. Sci. Biotechnol. 3(2), 141-158.

Neves, L., Oliveira, R. \& Alves, M. M. 2004 Influence of inoculum activity on the bio-methanization of a kitchen waste under different waste/inoculum ratios. Process Biochem. 39(12), 2019-2024.

Owens, J. M. \& Chynoweth, D. P. 1993 Biochemical methane potential of municipal solid-waste (MSW) components. Water Sci. Technol. 27(2), 1-14.

Pabon-Pereira, C. P., Castanares, G. \& van Lier, J. B. 2009 Optimizing an OxiTop protocol for screening plant material suitable for anaerobic digestion. submitted to Bioresource Technol.

Palmowski, L. M. \& Muller, J. A. 2000 Influence of the size reduction of organic waste on their anaerobic digestion. Water Sci. Technol. 47(12), 231-238.

Perez Lopez, C., Kyrchmayr, R., Neureiter, M. \& Braun, R. 2005 Effect of physical and chemical pre-treatments on methane yield from maize silage and grains. In proceedings of the International Symposium on Anaerobic Digesion of Solid
Waste (ISAD-SW) 2005. Copenhagen, Denmark, August 31Septmeber 3, 2005, p. 204-208.

Raposo, F., Banks, C. J., Siegert, I., Heaven, S. \& Borja, R. 2006 Influence of inoculum to substrate ratio on the biochemical methane potential of maize in batch tests. Process Biochem. 41(6), 1444-1450.

Raposo, F., de la Rubia, M. A., Borja, R. \& Alaiz, M. 2008 Assessment of a modified and optimised method for determining chemical oxygen demand of solid substrates and solutions with high suspended solid content. Talanta 76, $448-453$.

Rozzi, A. \& Remigi, E. 2004 Methods of assessing microbial activity and inhibition under anaerobic conditions: a literature review. Rev. Environ. Sci. Biotechnol. 3(2), 93-115.

Sanders, W. T. M., 200I Anaerobic hydrolysis during digestion of complex substrates. PhD Thesis, Wageningen University, Wageningen, Netherlands.

Vavilin, V. A. \& Angelidaki, I. 2005 Anaerobic degradation of solid material: importance of initiation centers for methanogenesis, mixing intensity, and 2D distributed model. Biotechnol. Bioeng. 89(1), 113-122.

Vavilin, V. A., Fernandez, B., Palatsi, J. \& Flotats, X. 2008 Hydrolysis kinetics in anaerobic degradation of particulate organic material: an overview. Waste Manage. 28(6), 941-953. 